Artigo Técnico

\title{
Plano de Segurança da Água: modelo conceitual para monitoramento de riscos à contaminação de água em comunidades rurais
}

\author{
Water Safety Plan: conceptual model for monitoring \\ of water contamination risks in rural communties
}

Rony Felipe Marcelino Corrêa'* ${ }^{1 *}$, Katia Sakihama Ventura' ${ }^{\circledR}$

\begin{abstract}
RESUMO
O Plano de Segurança da Água (PSA) contempla, entre outras etapas, a identificação e o acompanhamento de eventos perigosos e pode garantir qualidade hídrica aos consumidores. A ruralidade abrange cerca de 15\% da população brasileira e o acompanhamento técnico é insuficiente para atender às demandas locais. Nesse contexto, o principal objetivo foi elaborar um modelo conceitual de PSA para monitoramento de riscos à contaminação da água na área rural, contemplando eventos desde a captação até a distribuição de água em comunidades rurais. A metodologia consistiu em caracterização de eventos perigosos, concepção do modelo computacional, consulta a especialistas e calibração e aplicação do modelo em propriedades rurais. Entre os resultados, tem-se um software elaborado em Python contendo 109 eventos direcionados ao abastecimento rural. O programa analisou a precariedade no entorno da captação de água e as condições de limpeza das propriedades estudadas. Os resultados indicaram que os riscos mais elevados, em sua maioria, são provenientes do uso de fossa negra, descarte irregular de resíduos sólidos, lançamento de esgoto doméstico a céu aberto e criação de animais nas proximidades da captação de água. Não há softwares disponíveis para mensuração de riscos ao abastecimento de água em áreas rurais e o modelo proposto pode ser utilizado para avaliação da salubridade rural no contexto nacional. Dessa forma, o software subsidia o monitoramento dos recursos hídricos e amplia a capacidade de gerenciamento no setor.
\end{abstract}

Palavras-chave: abastecimento de água; gestão de risco; segurança da água; captação de água.

\begin{abstract}
The Water Safety Plan (WSP) includes, among other steps, the identification and monitoring of dangerous events can guarantee water quality to consumers. Rurality covers about $15 \%$ of the Brazilian population and technical support is insufficient to assist local demands. In this context, the main objective was to develop a conceptual WSP model for monitoring water contamination risks in the rural area, contemplating events from water catchment to water distribution in rural communities. The methodology consisted of the characterization of dangerous events, conception of the computational model, specialists consultation, and model calibration and application in rural properties. Among the results, there is a software elaborated in Python containing 109 events aimed at rural supply. The program analyzed the precariousness around the water catchment and the clean conditions of the studied properties. These results indicated the highest risks, for the most part, come from the use of cesspool, irregular disposal of solid waste, domestic sewage discharge, and animal beeding nearby water catchment. There is no software available to measure water supply risks in rural areas and the proposed model can be used for environmental health evaluatiation in the national context. In this way, the software can support water resource monitoring and expands the manageability in the sector
\end{abstract}

Keywords: water supply; risk management; water safety; water catchment

\section{INTRODUÇÃO}

A Organização Mundial da Saúde (OMS) recomenda que a população tenha acesso à água potável para consumo humano (WHO, 2017). Os critérios que garantem os padrões de potabilidade seguem abordagem corretiva com os parâmetros de qualidade da água (WHO, 2017; MANCUSO; SOUZA, 2015;

MARTINHO; MENDES, 2015). Nesse sentido, mecanismos voltados à prevenção, como o Plano de Segurança da Água (PSA), são úteis para ampliar a capacidade da gestão hídrica.

A Agenda 2030 é outra ferramenta que busca a segurança dos recursos hídricos, especialmente no $6^{\circ}$ Objetivo de Desenvolvimento do Milênio (ODM),

口

'Programa de Pós-Graduação em Engenharia Urbana, Universidade Federal de São Carlos - São Carlos (SP), Brasil. *Autor correspondente: ronycorrea@hotmail.com

Conflitos de interesse: os autores declaram não haver conflito de interesses.

Financiamento: Coordenação de Aperfeiçoamento de Pessoal de Nível Superior (CAPES) - Código de Financiamento 001

Recebido: 31/03/2019 - Aceito: 26/03/2020 - Reg. ABES: 20190394 
ao "assegurar a disponibilidade e gestão sustentável da água e saneamento para todas e todos" (ONU, 2019).

Em comunidades com salubridade afetada, outros ODM estão diretamente relacionados ao PSA, pois, à medida que são mitigados, minimiza-se a ação de outros. Entre os que podem atuar conjuntamente nessa lógica, destacam-se a erradicação da pobreza $\left(1^{\circ}\right)$, a fome zero e a agricultura sustentável $\left(2^{\circ}\right)$, o consumo e a produção responsáveis $\left(12^{\circ}\right)$, entre outros objetivos de forma indireta (ONU, 2019).

Quanto aos instrumentos legais, a Portaria de Consolidação no 5, de 28 de setembro de 2017, ressalta, no inciso IV do artigo 13, a importância do monitoramento do Sistema de Abastecimento de Água (SAA), quanto aos riscos à saúde humana (BRASIL, 2017).

Os principais objetivos do PSA são prevenir ou minimizar a contaminação da água, reduzir ou remover a contaminação por processos de tratamento apropriados e prevenir a contaminação nas fases de armazenamento, distribuição e manuseio de água potável (WHO, 2017).

O desenvolvimento do PSA requer atenção cuidadosa em cada uma das cinco fases: etapas preliminares; avaliação do sistema; monitoramento operacional; planos de gestão; e validação e verificação, segundo Brasil (2012) e Vieira e Morais (2005).

Nesse contexto, o controle da qualidade da água para abastecimento no país é efetuado pelos órgãos de fiscalização, pelas autarquias e por empresas de saneamento que atuam no setor. No entanto, indicadores e programas computacionais integrados à mensuração do risco de contaminação do recursos hídrico não estão disponíveis para a gestão hídrica, particularmente na área rural.

O PSA avalia os desafios do SAA e auxilia o planejamento de ações para minizar os riscos, especialmente, de eventos com maior grau de controle.

De acordo com a norma técnica NBR ISO 31000, da Associação Brasileira de Normas Técnicas (ABNT), a gestão de risco consiste em identificar, analisar e avaliar os riscos para posterior tratamento com eficiência, eficácia e consistência (ABNT, 2018). A implementação de ações socioeducativas, a gestão de recursos hídricos e o monitoramento de eventos perigosos possibilitam o alcance dessas premissas (BRASIL, 2012).
Perigo é o dano provocado à saúde pública por agentes físicos, químicos, biológicos. Os eventos perigosos ou fontes de poluição/contaminação representam circunstâncias que causam danos e oferecem risco ao abastecimento de água (RASHON, 2009; WHO, 2005).

Nesse contexto, os serviços de saneamento são garantidos pela Política Nacional de Saneamento Básico (PNSB), regulamentada pela Lei Federal $\mathrm{n}^{\circ}$ 11.445, de 5 de janeiro de 2007 (BRASIL, 2007).

O Plano Nacional de Saneamento Básico (PLANSAB) apontou necessidade de investimento em saneamento rural para, até o ano de 2035, elevar o acesso à água potável em até $80 \%$ e ampliar em, aproximadamente, $70 \%$ a coleta de resíduos sólidos e de esgoto sanitário (BRASIL, 2013).

O Programa Nacional de Saneamento Rural (PNSR), elaborado em dezembro de 2019, tem o intuito de intensificar o controle da qualidade da água em sistemas e soluções alternativas e individuais de abastecimento de água, bem como implementar o PSA no meio rural (BRASIL, 2019).

As soluções coletivas e individuais (Quadro 1), propostas pelo Ministério da Saúde, visam o controle e o monitoramento de poços, rios e lagos que abastecem as propriedades rurais (BRASIL, 2019). Mas, sobretudo, incluem a limpeza e manutenção da infraestrutura rural.

O levantamento aponta que a consolidação das comunidades determina o tipo de captação e distribuição da água. Aglomerações consolidadas tendem a apresentar soluções coletivas, diferentemente de ocupações recentes que adotam soluções individuais (BRASIL, 2019).

No Brasil, cerca de $15 \%$ da população brasileira vive na zona rural, sendo que a maioria dos domicílios (70\%) não está ligada à rede de distribuição de água e mais de $20 \%$ deles não têm tubulações no interior de suas residências para fornecer água ao consumo (IBGE, 2015). Esse diagnóstico informa que 5\% dos domicílios têm rede coletora de esgoto sanitário, $43 \%$ têm fossa rudimentar, $10 \%$ apresentam banheiro e $65 \%$ não têm qualquer ação de coleta de resíduos sólidos.

Segundo Vilar (2011), a heterogeneidade no meio rural se confirma pela diversidade de constituição das comunidades brasileiras, o que exige intervenções particulares em saneamento básico e também nos aspectos ambientais, socioeducativos e sustentáveis.

Quadro 1 - Matriz de soluções operacionais rotineiras e não rotineiras ao abastecimento de água no meio rural.

\begin{tabular}{|c|c|c|c|c|}
\hline Soluções & Captação & $\begin{array}{c}\text { Operação rotineira - } \\
\text { específica a cada tecnologia }\end{array}$ & $\begin{array}{c}\text { Operação rotineira - } \\
\text { comum a todas as tecnologias }\end{array}$ & $\begin{array}{c}\text { Operação não rotineira } \\
\text { (comum a todas as tecnologias) }\end{array}$ \\
\hline Coletivas & $\begin{array}{l}\text { Superficial e } \\
\text { subterrânea }\end{array}$ & $\begin{array}{l}\text { Monitorar o nível de água em poços } \\
\text { de captação } \\
\text { Assegurar a proteção física de } \\
\text { estruturas de captação, com especial } \\
\text { atenção à tomada de água em } \\
\text { aquíferos livres e nascentes. }\end{array}$ & $\begin{array}{c}\text { Realizar limpeza da área de entorno } \\
\text { Assegurar proteção física e segurança } \\
\text { às estruturas de captação } \\
\text { Monitorar as condições físicas e } \\
\text { estruturais do ponto de captação de água } \\
\text { Monitorar as condições de funcionamento das } \\
\text { instalações e equipamentos de captação de água }\end{array}$ & $\begin{array}{l}\text { Realizar manutenção periódica da } \\
\text { integridade física e estrutural } \\
\text { Realizar manutenção periódica } \\
\text { das instalações e equipamentos de } \\
\text { captação de água }\end{array}$ \\
\hline \multirow[t]{2}{*}{ Individuais } & $\begin{array}{l}\text { Superficial e } \\
\text { subterrânea }\end{array}$ & $\begin{array}{l}\text { Monitorar o nível de água em poços } \\
\text { de captação Assegurar a proteção } \\
\text { física de estruturas de captação, com } \\
\text { especial atenção às tomadas de água } \\
\text { em aquíferos livres e nascentes }\end{array}$ & \multirow{2}{*}{$\begin{array}{l}\text { Realizar limpeza da área de entorno } \\
\text { Assegurar proteção física e segurança } \\
\text { às estruturas de captação } \\
\text { Monitorar as condições físicas e } \\
\text { estruturais do ponto de captação de água } \\
\text { onitorar as condições de funcionamento das } \\
\text { alações e equipamentos de captação de água }\end{array}$} & \multirow{2}{*}{$\begin{array}{c}\text { Realizar manutenção periódica da } \\
\text { integridade física e estrutural } \\
\text { Realizar manutenção periódica } \\
\text { das instalações e equipamentos de } \\
\text { captação de água }\end{array}$} \\
\hline & Água pluvial & $\begin{array}{l}\text { Limpar telhados e calhas antes de } \\
\text { cada estação chuvosa } \\
\text { Descartar a água das primeiras chuvas. }\end{array}$ & & \\
\hline
\end{tabular}

Fonte: Brasil (2019). 
Entre as práticas que impactam o meio rural, destacam-se o descarte inadequado de resíduos recicláveis, a criação de animais em área ribeirinha, o vazamento de combustível em área de manancial, a erosão e o assoreamento do corpo hídrico, o uso inadequado de fertilizantes, os despejos industriais, entre outros (ONU, 2019; MELLANBY, 1982; RASHON, 2009; DORST, 1973). A contaminação de água no meio rural pode ocorrer pelo uso de recipientes inadequados, pela falta de cuidado próximo às captações subterrânea e superficial, pelo mau armazenamento de água pluvial, entre outros (BRASIL, 2009; 2015; GOMEZ; SORLINI; COLLIVIGNARELLI, 2014; GUNDRY et al., 2006; WRIGHT; GUNDRY; CONROY, 2004).

As condições de salubridade estão associadas ao déficit de infraestrutura e interferem na qualidade de vida, especialmente de núcleos rurais, pois esses serviços são, em sua maioria, direcionados à área urbana, conforme Vilar (2011).

No caso de pequenas comunidades, melhorar o acesso à água potável contribui diretamente para as condições de saúde porque reduz a pobreza e, consequentemente, influencia o desenvolvimento educacional e os meios de subsistência sustentáveis (WHO, 2014).

Em alguns países, o desafio é evitar a contaminação de água em vilas e distritos. Na Islândia, as captações estão localizadas em região vulcânica e o forte odor de enxofre é presente. Nos últimos 20 anos, foram registradas doenças transmitidas pela água em instalações de água em pequenos núcleos, segundo Gunnarsdóttir e Gissurarson (2008).

Experiências internacionais com a implantação do PSA indicam que as fontes de contaminação hídrica mais frequentes ocorrem pelo uso indiscriminado de agrotóxicos e de fertilizantes perto da captação, pela contaminação por fezes animais ou por resíduos domiciliares descartados inadequadamente no solo e rios, pela ruptura de barragem de rejeitos nas proximidades da captação, pela presença de água parada ao redor do poço ou cisterna, por ações de vandalismo, falhas elétricas ou mecânicas no sistema de bombeamento (GARCÍA et al., 2018; SORLINI et al., 2017; YE et al., 2015; BRAGA, 2015; MAYNILAD WATER SERVICES, 2019; RONDI, 2014; WHO, 2014; NIJHAWAN et al., 2014; SILVA, 2013; WORLD BANK, 2010; ITN-BUET, 2006; VIEIRA; MORAIS, 2005; WHO, 2005).

Estudos sobre segurança da água e métodos de avaliação de riscos são necessários, mas pouco conhecidos (VENTURA; VAZ FILHO; NASCIMENTO, 2019). Os autores apresentam os desafios do PSA à gestão dos recursos hídricos e as oportunidades da ferramenta (Quadro 2), tais como a necessidade de divulgação do PSA e seu uso aplicado aos meios urbano e rural.

O objetivo principal foi elaborar, a partir das recomendações da OMS, um modelo conceitual do PSA para monitoramento de risco à contaminação hídrica em comunidades rurais.

\section{METODOLOGIA}

As fontes de contaminação da água no meio rural foram obtidas por dados secundários relativos a saneamento rural e alternativas de abastecimento de água, risco para água potável, instrumentos legais e manuais técnicos para segurança da água, desafios ao monitoramento e à prevenção da gestão de recursos hídricos e experiências internacionais e nacionais ( $1^{\text {a }}$ Fase). Esselevantamento contribuiu para a identificação de eventos perigosos ao Sistema de Abastecimento de Água Rural (SAA Rural) e para a elaboração de mapa populacional presente na ruralidade.
Quadro 2 - Oportunidades e desafios do Plano de Segurança da Água.

\begin{tabular}{|c|c|}
\hline Oportunidades & Desafios \\
\hline $\begin{array}{c}\text { Formação de grupo de profissionais } \\
\text { com expertise no assunto para } \\
\text { auxiliar municípios com o mesmo } \\
\text { propósito; } \\
\text { Inspiração a outros gestores em } \\
\text { busca de experiências promissoras; } \\
\text { Otimização de esforços e recursos } \\
\text { para atingir resultados eficazes; } \\
\text { Melhoria das práticas de gestão no } \\
\text { sistema de abastecimento de água; } \\
\text { Ampliação do conhecimento da } \\
\text { cadeia produtora de água pela } \\
\text { identificação de pontos vulneráveis no } \\
\text { sistema de abastecimento; } \\
\text { Estabelecimento de parceria entre } \\
\text { entidades; } \\
\text { Melhoria da capacitação técnica } \\
\text { com apoio de especialistas e de } \\
\text { experiências bem-sucedidas. }\end{array}$ & $\begin{array}{c}\text { Estabelecimento de modelo de PSA de } \\
\text { forma articulada entre os setores e os } \\
\text { Órgãos de gestão hídrica; } \\
\text { Universalização do PSA como } \\
\text { ferramenta útil e contínua em todo o } \\
\text { território nacional; } \\
\text { Aplicação da ferramenta em soluções } \\
\text { alternativas de abastecimento de água } \\
\text { com o envolvimento da sociedade } \\
\text { local; } \\
\text { Investimentos no controle e no } \\
\text { monitoramento de forma preventiva; } \\
\text { Envolvimento de profissionais da alta } \\
\text { administração na tomada de decisões } \\
\text { para efetividade do plano; } \\
\text { Ausência de estudos dessa natureza } \\
\text { no meio rural, tanto nos aspectos } \\
\text { metodológicos quanto para } \\
\text { implantação do plano à gestão hídrica. }\end{array}$ \\
\hline
\end{tabular}

Fonte: Ventura, Vaz Filho e Nascimento (2019).

Com os eventos organizados por etapa e por componente do sistema, elaborou-se o modelo conceitual ( $2^{a}$ Fase), tendo como base a teoria de sistemas, a estruturação do banco de dados e o uso da matriz de priorização de risco (Quadro 3).

Um sistema representa a associação de componentes que se inter-relacionam para atingir a mesma finalidade, segundo Sommerville (2004). O modelo conceitual apresenta as informações que esse sistema contempla e o foco deve estar direcionado ao problema, e não à solução (FALBO; BARCELLOS, 2011).

A estruturação do modelo deve contemplar os requisitos do usuário (funções e restrições de operação do sistema) e os requisitos do sistema, os quais podem ser funcionais (orientações à operação do modelo) e não funcionais (restrição de função do sistema), segundo Sommerville (2004).

Os critérios estabelecidos pelos pesquisadores foram adaptados de WHO (2017), Brasil (2012) e Vieira e Morais (2005), e representam o grau de severidade e de ocorrência do evento. O produto desses critérios indica o risco do evento (Quadro 3), sendo que quanto maior é o score, maior será o risco de contaminação hídrica (Figura 1).

A interface gráfica do banco de dados foi desenvolvida em linguagem Python. O programa seguiu as etapas e os procedimentos, sugeridos pela OMS, para desenvolvimento do PSA Rural (WHO, 2017; BRASIL, 2012). Os dados de entrada são os critérios adotados para cada evento observado em campo e os resultados do programa são o Score (nota) de cada evento e as medidas de controle para mitigar os eventos avaliados.

O software foi submetido ao Comitê de Ética em Pesquisa (CEP) para aprovação ( $3^{\mathrm{a}}$ Fase). Os especialistas foram selecionados por meio de amostra intencional na Plataforma Lattes do Conselho de Desenvolvimento Científico e Tecnológico $(\mathrm{CNPq})$, com perfil voltado a trabalhos técnicos em saneamento, à atuação como pesquisador ou funcionário de empresa de saneamento, à existência de publicações em PSA e à publicação de pesquisas no tema. 
Quadro 3 - Matriz de priorização de riscos.

\begin{tabular}{|l|c|c|c|c|c|}
\hline \multirow{2}{*}{$\begin{array}{l}\text { Probabilidade } \\
\text { de ocorrência } \\
\text { do evento }\end{array}$} & \multicolumn{5}{|c|}{ Severidade/consequência do evento } \\
\cline { 2 - 7 } & Insignificante & Baixa & Moderada & Grave & $\begin{array}{l}\text { Muito } \\
\text { grave }\end{array}$ \\
\hline Quase certo & 5 & 10 & 15 & 20 & 25 \\
\hline Muito frequente & 4 & 8 & 12 & 16 & 20 \\
\hline Frequente & 3 & 6 & 9 & 12 & 15 \\
\hline Pouco frequente & 2 & 4 & 6 & 8 & 10 \\
\hline Raro & 1 & 2 & 3 & 4 & 5 \\
\hline
\end{tabular}

Fonte: elaborado por Corrêa (2020), com base em WHO (2017), Brasil (2012), Vieira e Morais (2005).

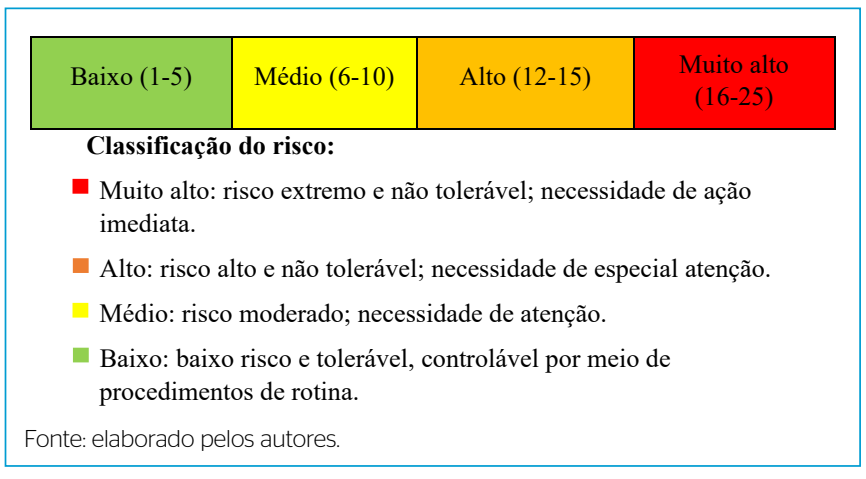

Figura 1 - Score (nota) e classificação de risco quanto à probabilidade de ocorrência e severidade do evento.
A calibração do modelo foi realizada em cinco propriedades rurais do município de São Carlos e a aplicação do software foi realizada em cinco propriedades de um assentamento rural do município de Araraquara (4a Fase), ambos no interior paulista.

\section{RESULTADOS E DISCUSSÃO}

Os resultados, apresentados neste item, seguem a estruturação metodológica.

\section{Elaboração de mapa populacional e identificação de eventos perigosos (fase 1)}

Com dados da Pesquisa Nacional por Amostra de Domicílios (IBGE, 2015), Corrêa (2020) elaborou a Figura 2, que ilustra a distribuição da população rural por estado no Brasil.

A concentração de população em áreas rurais está em maior representatividade no estado da Bahia, seguido por Minas Gerais (Figura 2).

O modelo conceitual contemplou 109 eventos perigosos para o modelo conceitual, os quais foram organizados por etapa e componente do sistema (Quadro 4). A lista completa está disponível na pesquisa de Corrêa (2020).

\section{Concepção da ferramenta computacional (fase 2)}

O PSA deve contemplar todos os componentes do sistema (Figura 3), visando a avaliação de riscos para a segurança da água.

A Figura 4 ilustra a página de abertura do programa e a Figura 5 apresenta os campos a serem preenchimentos pelo usuário na etapa preliminar do PSA.

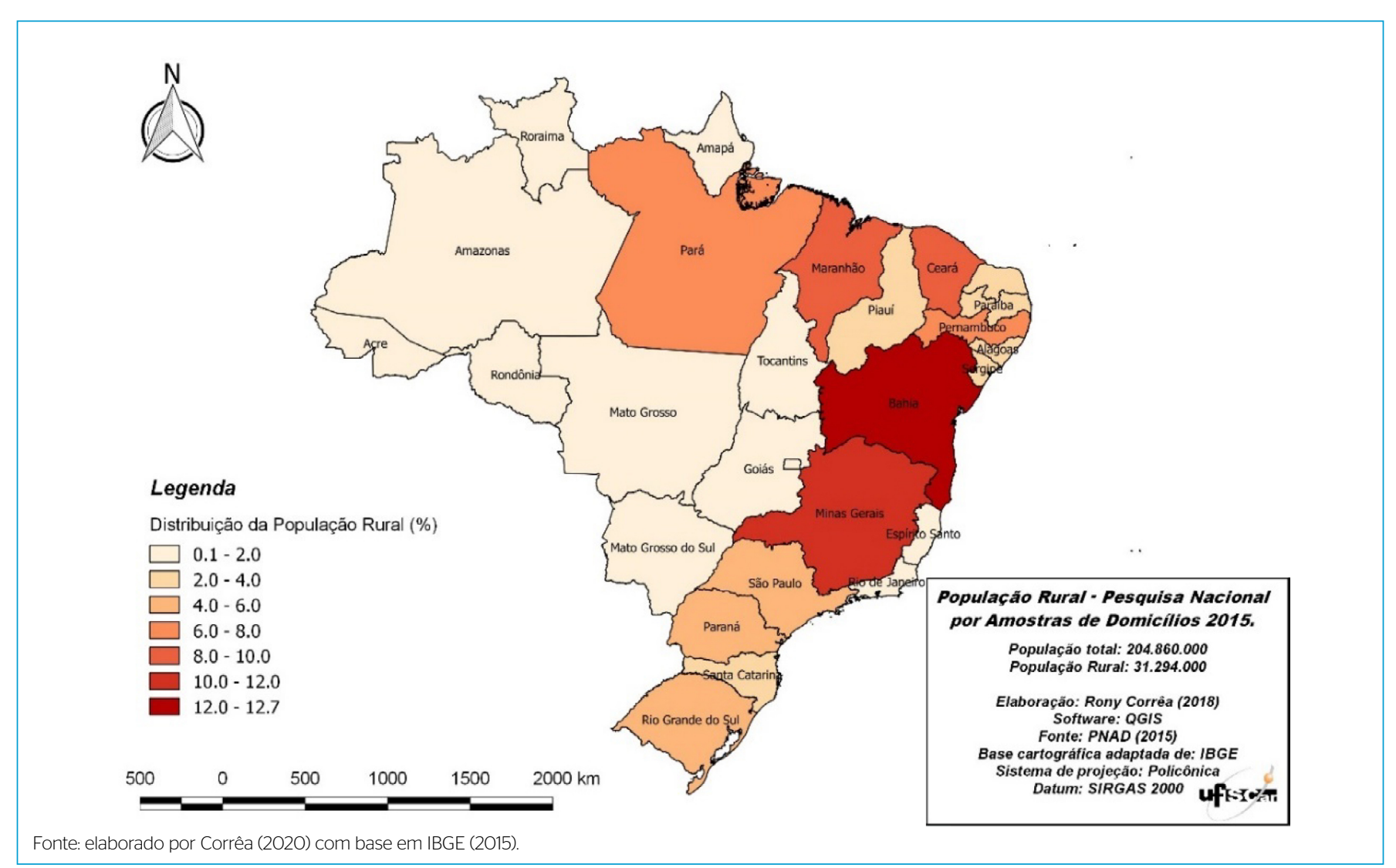

Figura 2 - Distribuição da populacional rural por estado brasileiro. 
Quadro 4 - Eventos perigosos para avaliação do Sistema de Abastecimento de Água Rural (extrato).

\begin{tabular}{|c|c|c|}
\hline Etapa/quantidade & Componente do sistema & Exemplo de evento perigoso \\
\hline \multirow{3}{*}{ Captação (58) } & Superficial (24) & $\begin{array}{l}\text { - Presença elevada de algas na área de captação / sinais de eutrofização } \\
\text { - Erosão provocada por acúmulo de sedimentos } \\
\text { - Carreamento de resíduos agrícolas e de resíduos urbanos na captação } \\
\text { - Presença de carcaças de animais ao redor da fonte de captação }\end{array}$ \\
\hline & Subterrânea (25) & $\begin{array}{l}\text { - Acúmulo de fezes entorno da fonte de captação } \\
\text { - Comprometimento do funcionamento de dispositivos no poço } \\
\text { - Entrada de água por equipamentos danificados e por meio de rachaduras e } \\
\text { orifícios nas tubulações do poço } \\
\text { - Drenagem insuficiente e acúmulo de água no entorno do poço }\end{array}$ \\
\hline & Ambas (09) & $\begin{array}{l}\text { - Chuvas intensas com alteração da turbidez da água } \\
\text { - Falha elétrica ou mecânica do sistema de captação } \\
\text { - Lavagem de roupas e banho na área de captação } \\
\text { - Falta de sinalização / alerta na área de captação }\end{array}$ \\
\hline Tratamento (06) & Processo (06) & $\begin{array}{l}\text { - Falta de controle na quantidade de produto químico e dosagem } \\
\text { - Ausência de medidas de segurança no armazenamento de produtos químicos }\end{array}$ \\
\hline Reservatório (12) & Condições de armazenamento (12) & $\begin{array}{l}\text { - Corrosão de materiais de construção } \\
\text { - Infiltração/vazamento de água } \\
\text { - Acesso livre a animais }\end{array}$ \\
\hline \multirow[b]{2}{*}{ Distribuição (15) } & Transporte por caminhão-pipa/outros (07) & $\begin{array}{l}\text { - Contaminação da água por falta de tampa ou proteção inadequada } \\
\text { - Perda de água no tanque/recipiente }\end{array}$ \\
\hline & Operação e distribuição de água (O8) & $\begin{array}{l}\text { - Tubulações de esgoto e de água muito próximas (contaminação cruzada) } \\
\text { - Existência de ponto de vazamento (perda de água) } \\
\text { - Práticas de higiene inadequadas durante reparo de tubulações }\end{array}$ \\
\hline \multirow{2}{*}{ Usuário (18) } & Coleta de água (08) & $\begin{array}{l}\text { - Torneira ou acessórios (mangueiras; tubos de coleta) insalubres } \\
\text { - Coleta com recipiente inadequado, danificado ou sujo } \\
\text { - Presença de fossa negra próxima à fonte de captação }\end{array}$ \\
\hline & Manuseio e armazenamento doméstico (10) & $\begin{array}{l}\text { - Filtração com tecidos ou equipamentos sujos } \\
\text { - Utilização de copos sujos para consumir água } \\
\text { - Armazenamento em recipiente sem tampa e/ou danificados }\end{array}$ \\
\hline
\end{tabular}

Fonte: Corrêa (2020).

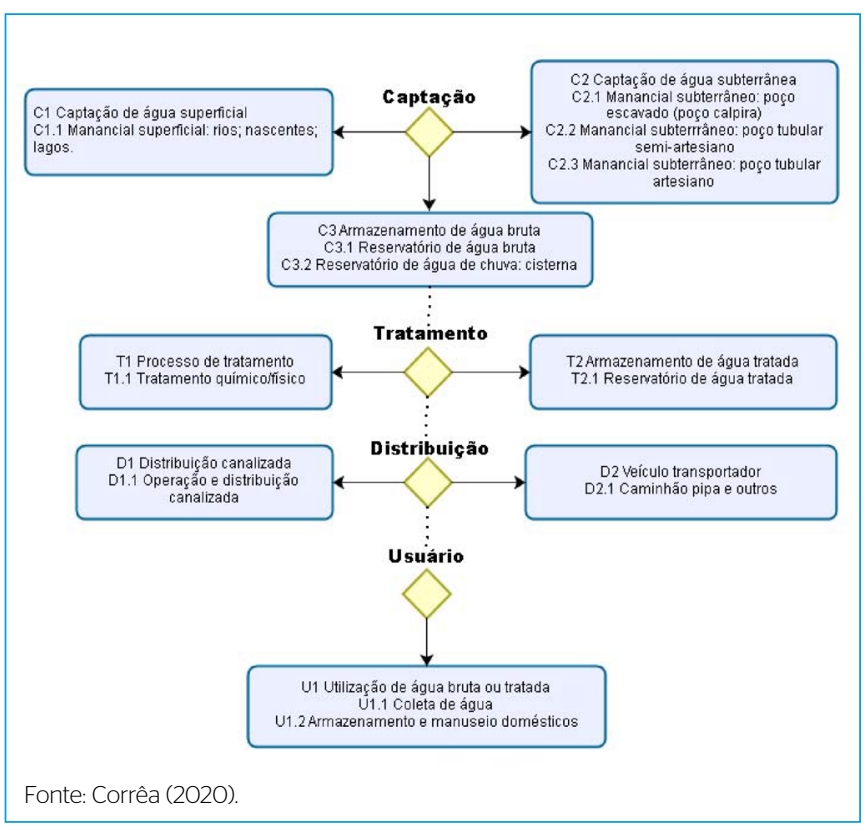

Figura 3 - Representação conceitual do sistema para estruturação do Plano de Segurança da Água em comunidades rurais.
O relatório apresenta os códigos dos eventos considerados na análise pelo usuário, o grau de risco avaliado e as medidas de controle para cada evento (Figura 6). O gráfico de barras e a cor associada ao grau do evento ilustram a condição sanitária observada no local (Figura 7).

As Figuras 6 e 7 ilustram os resultados das fases de avaliação do sistema e planos de gestão. Assim, o software pode ser utilizado para validação e verificação metodológica, bem como ao monitoramento de áreas que carecem de infraestrutura rural.

A ferramenta permite a inserção de novos eventos em cada etapa e os resultados gerados pelo software podem ser utilizados em análises posteriores, quando salvos em Portable Document Format (PDF).

\section{Submissão do software ao Comitê de Ética em Pesquisa (fase 3)}

O instrumento foi aprovado pelo CEP sob número de registro do Certificado de Apresentação para Apreciação Ética (CAAE) 14914919.9.0000.5504, o qual pode ser consultado pela Plataforma Brasil, do Ministério da Saúde.

As principais observações dos especialistas trataram da melhoria de descrição dos eventos e de sugestões para mensuração de eventos não observados durante a pesquisa. 


\section{Calibração e aplicação do software (fase 4)}

O programa foi validado em cinco comunidades rurais de São Carlos e aplicado em outras cinco, no assentamento rural em Araraquara, ambos municípios do interior de São Paulo.

Para ilustração das informações, apresentam-se, resumidamente, os resultados gerados pela calibração e aplicação do programa, especificamente para as captações de água.

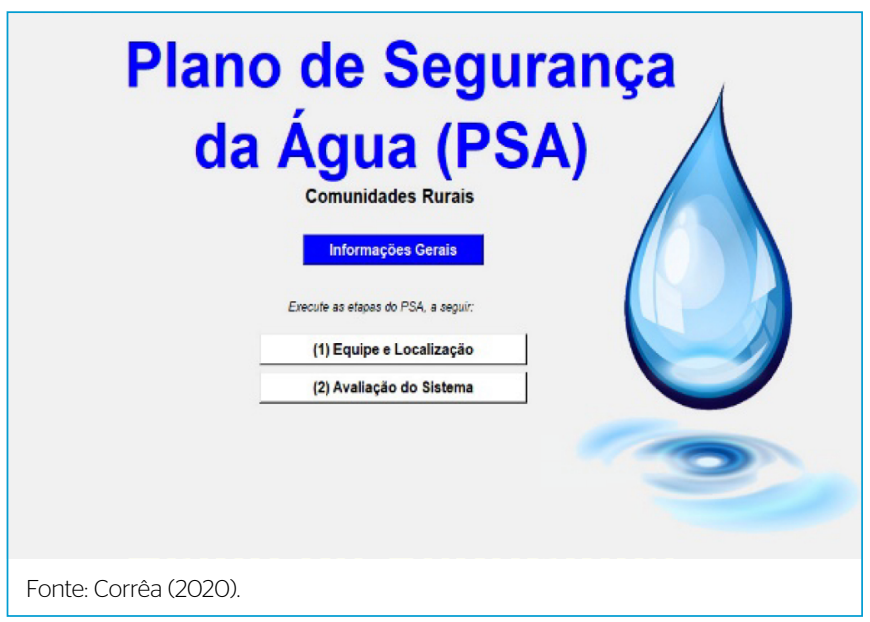

Figura 4 - Layout do programa para Plano de Segurança da Água.
Do total de eventos observados em uma propriedade de São Carlos-SP (17), 8 deles foram classificados com risco elevado (Quadro 5):

- falta de proteção/cerca imprópria, permitindo acesso de animais e de pessoas;

- falta de placa de aviso/alerta para resguardar a captação;

- presença de animais ao lado/próximo da fonte de captação;

- falha elétrica;

- presença de pessoas com comportamento inadequado e falta de higiene próximo da fonte;

- lavagem de roupas e banho na área de captação;

- lançamento inadequado de efluentes/águas residuárias nos cursos d’água.

Dos 17 eventos identificados por Corrêa (2020), o software apontou que 6 são de origem domiciliar e 5 deles têm risco alto de contaminação (Quadro 5 e Figura 8).

Não foram identificados, momentaneamente, eventos com risco elevado (score acima de 15) de contaminação de água.

Em Araraquara-SP, dos cinco lotes visitados, três deles não foram observados risco perceptível no momento da avaliação. O abastecimento de água em todos os lotes é realizado por poço tubular semiartesiano. Os dados referem-se a dois lotes dessa comunidade.

No primeiro lote, do total de eventos observados em campo (12), a maioria (10) foi avaliada em alto risco de contaminação, principalmente pela pontuação máxima nesse nível, conforme Quadro 6 e Figura 9.

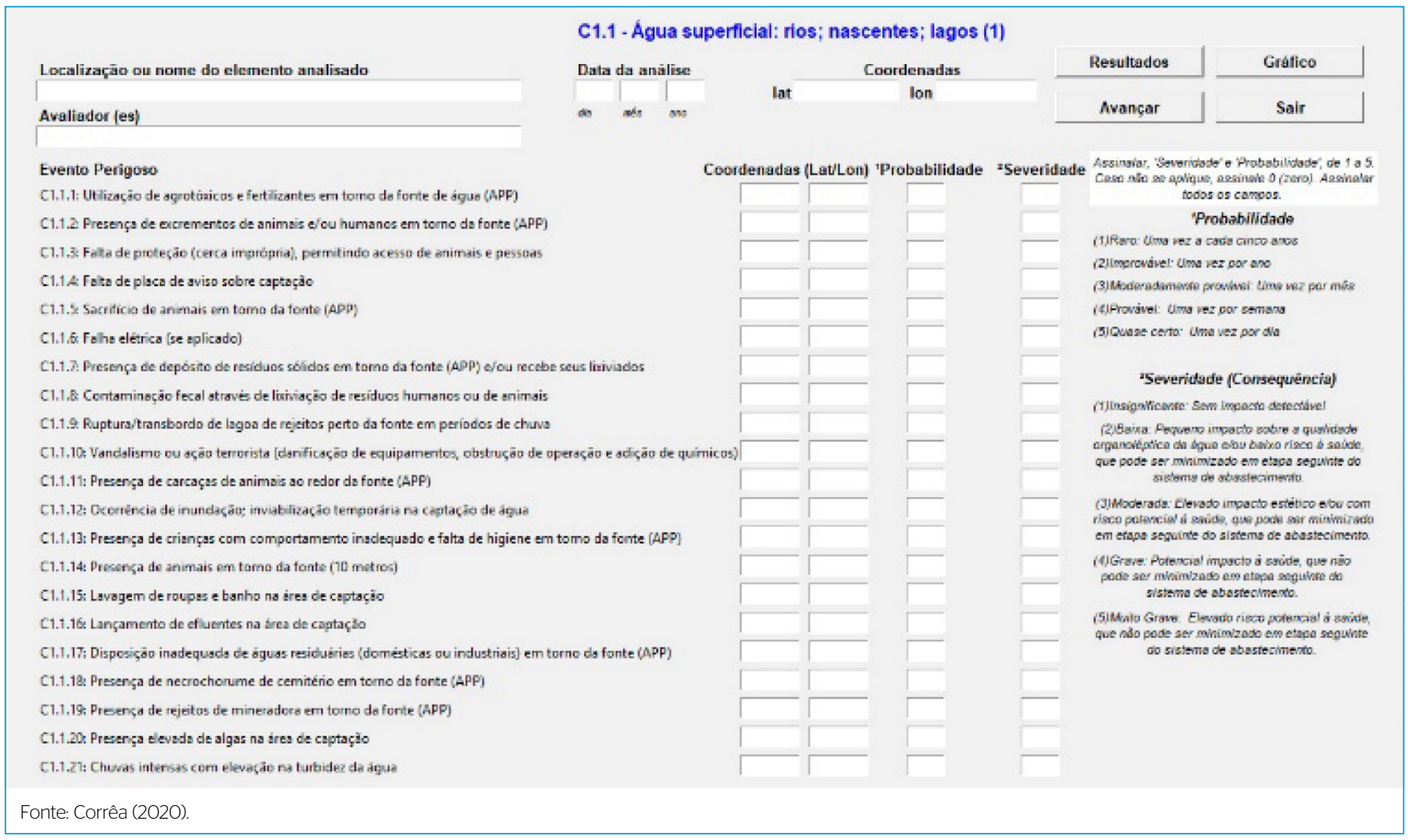

Figura 5 - Inserção de eventos perigosos na captação superficial. 


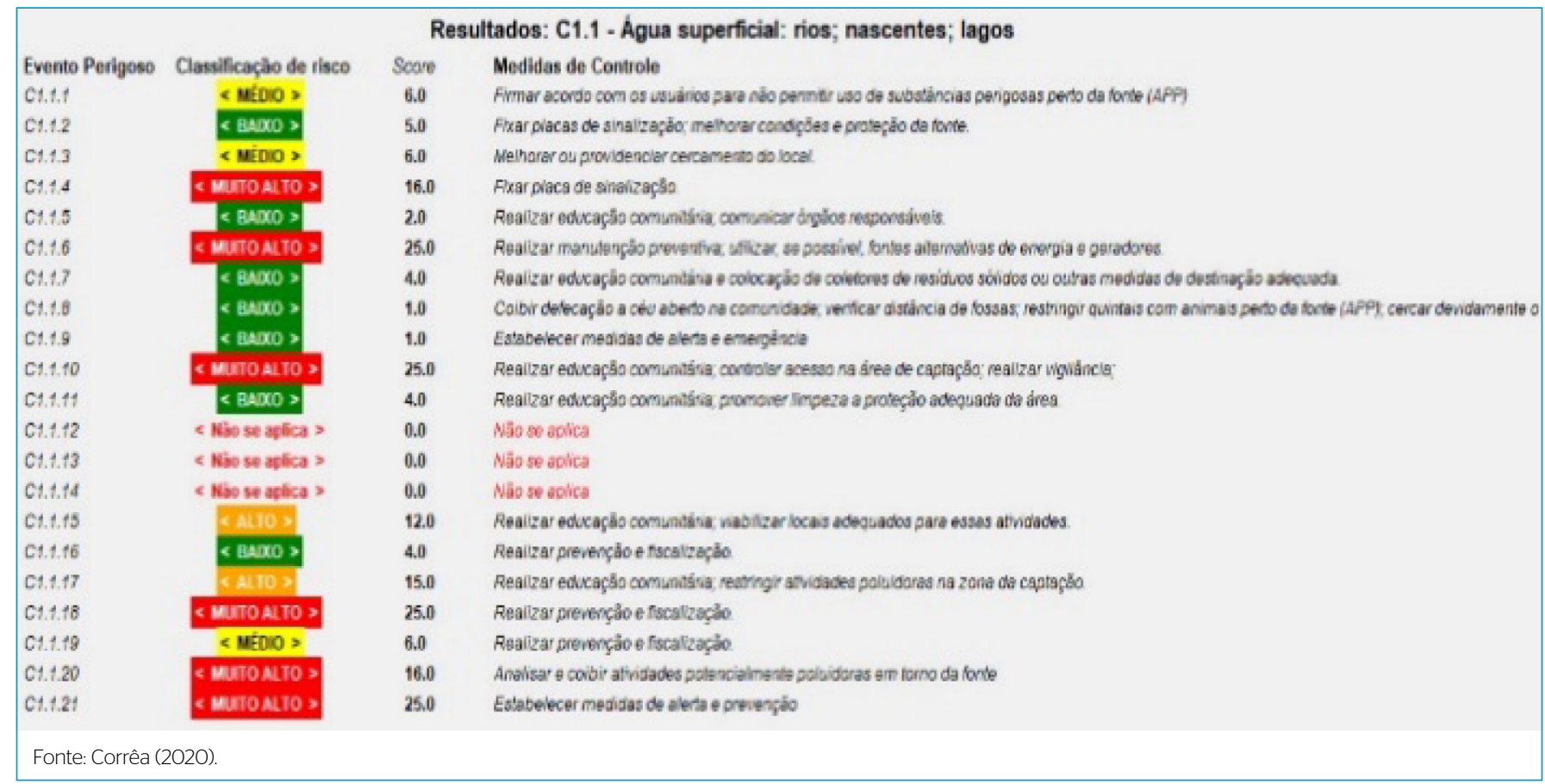

Figura 6 - Relatório dos riscos analisados na captação superficial (eventos selecionados pelo usuário).

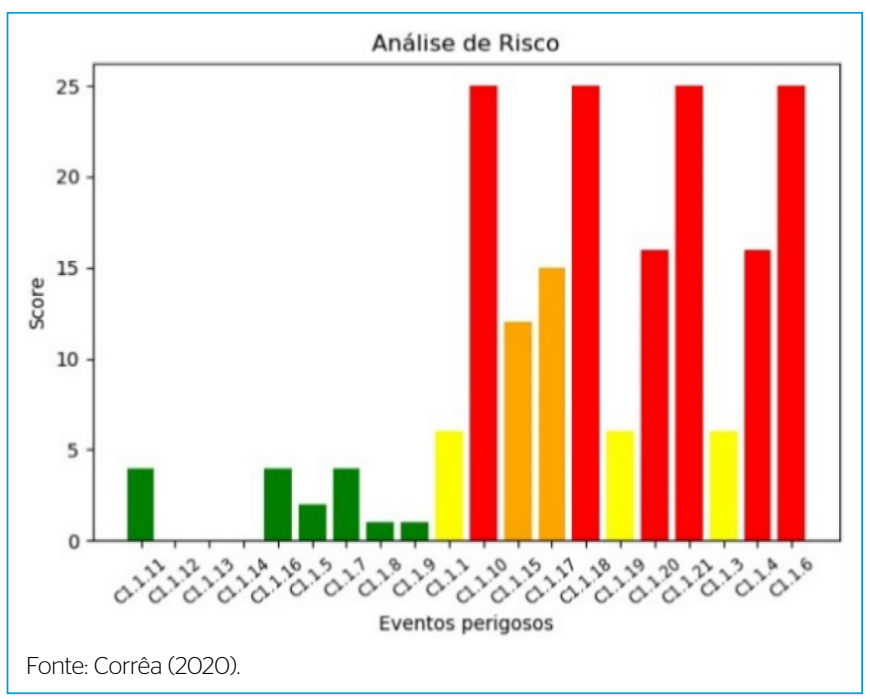

Figura 7 - Visualização do grau de risco dos eventos perigosos na captação superficial.

No segundo lote, do total de eventos observados (7), dois apresentaram risco alto de contaminação e estão relacionados a fezes de animais e à existência de outras fontes perto do poço, conforme Quadro 7 e pela Figura 10.

No momento da avaliação, o principal risco de contaminação da água decorre da presença de fezes e da criação de animais nas proximidades do poço.

Dos 7 eventos observados no segundo lote, o software permitiu ilustrar que as condições sanitárias exigem pouca adaptação. Porém, outras fontes de contaminação perto do poço foram identificadas com alto grau de risco (Figura 10).
Quadro 5 - Análise dos riscos observados para manancial superficial (C1.1) em São Carlos (nov. 2019).

\begin{tabular}{|c|c|c|c|}
\hline Código & Evento perigoso & Score & $\begin{array}{l}\text { Avaliação } \\
\text { de risco }\end{array}$ \\
\hline C1.1.3 & $\begin{array}{l}\text { Falta de proteção (cerca imprópria), permitindo } \\
\text { acesso de animais e pessoas }\end{array}$ & 15 & Alto \\
\hline C1.1.4 & Falta de placa de aviso sobre captação & 15 & Alto \\
\hline C1.1.6 & Falha elétrica & 12 & Alto \\
\hline C1.1.7 & $\begin{array}{l}\text { Presença de depósito de resíduos sólidos em } \\
\text { torno da fonte (APP) e/ou recebe seus lixiviados }\end{array}$ & 9 & Médio \\
\hline C1.1.8 & $\begin{array}{l}\text { Contaminação fecal através de lixiviação de } \\
\text { resíduos humanos ou de animais }\end{array}$ & 9 & Médio \\
\hline C1.1.10 & $\begin{array}{l}\text { Vandalismo (danificação de equipamentos, } \\
\text { obstrução de operação e adição de químicos) }\end{array}$ & 5 & Baixo \\
\hline C1.1.12 & $\begin{array}{l}\text { Ocorrência de inundação; inviabilização } \\
\text { temporária na captação de água }\end{array}$ & 6 & Médio \\
\hline C1.1.13 & $\begin{array}{l}\text { Presença de pessoas com } \\
\text { comportamento inadequado e falta } \\
\text { de higiene em torno da fonte (APP) }\end{array}$ & 12 & Alto \\
\hline C1.1.14 & $\begin{array}{l}\text { Presença de animais em torno da fonte } \\
\text { (até } 10 \text { metros) }\end{array}$ & 15 & Alto \\
\hline C1.1.15 & Lavagem de roupas e banho na área de captação & 12 & Alto \\
\hline C1.1.16 & Lançamento de efluentes na área de captação & 12 & Alto \\
\hline C1.1.17 & $\begin{array}{l}\text { Lançamento inadequado de águas residuárias } \\
\text { (domésticas ou industriais) em torno da fonte (APP) }\end{array}$ & 12 & Alto \\
\hline C1.1.21 & Chuvas intensas com elevação na turbidez da água & 9 & Médio \\
\hline C1.1.22 & Falha mecânica e estrutural no sistema de captação & 9 & Médio \\
\hline C1.1.23 & $\begin{array}{l}\text { Ocorrência de seca e/ou cheias prolongadas, } \\
\text { inviabilizando a captação }\end{array}$ & 9 & Médio \\
\hline C1.1.24 & $\begin{array}{l}\text { Entupimentos e/ou assoreamento na área de } \\
\text { captação }\end{array}$ & 9 & Médio \\
\hline C1.1.29 & $\begin{array}{c}\text { Escoamento de resíduos agrícolas e/ou de áreas } \\
\text { urbanizadas na área de captação }\end{array}$ & 6 & Médio \\
\hline
\end{tabular}

Fonte: Corrêa (2020) 


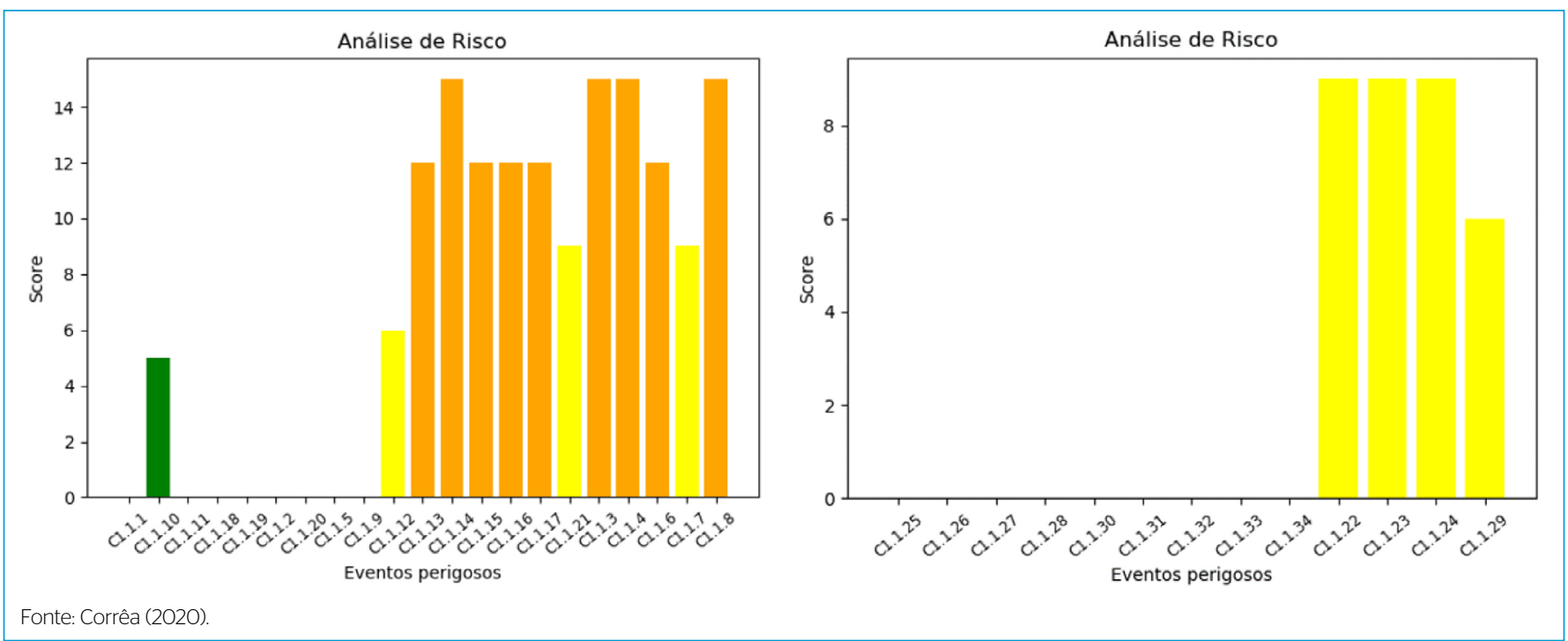

Figura 8 - Riscos observados na captação de água superficial de uma propriedade rural em São Carlos (nov. 2019).

Quadro 6 - Análise de riscos para manancial subterrâneo (C2.2) em Araraquara (nov. 2019): lote 1.

\begin{tabular}{|c|c|c|c|}
\hline Código & Evento perigoso & Score & $\begin{array}{l}\text { Avaliação } \\
\text { de risco }\end{array}$ \\
\hline C2.2.1 & $\begin{array}{l}\text { Entrada de água contaminada por meio de } \\
\text { rachaduras, orifícios e equipamentos danificados }\end{array}$ & 15 & Alto \\
\hline $\mathrm{C} 2.2 .2$ & $\begin{array}{l}\text { Presença de água estagnada ao redor do poço, } \\
\text { devido à má drenagem }\end{array}$ & 15 & Alto \\
\hline C2.2.3 & Entrada de água contaminada durante inundações & 6 & Médio \\
\hline $\mathrm{C} 2.2 .4$ & Contaminação no equipamento de saída do poço & 15 & Alto \\
\hline $\mathrm{C} 2.2 .5$ & Falha no sistema elétrico ou na bomba & 2 & Baixo \\
\hline $\mathrm{C} 2.2 .7$ & $\begin{array}{l}\text { Presença de latrina (fossa negra) ou local de } \\
\text { defecação a menos de } 10 \text { metros do poço }\end{array}$ & 15 & Alto \\
\hline C2.2.9 & $\begin{array}{l}\text { Presença de excrementos de animais ou } \\
\text { humanos em torno do poço }\end{array}$ & 15 & Alto \\
\hline C2.2.11 & Limpeza e higiene inadequadas no poço & 15 & Alto \\
\hline C2.2.12 & Tubulações sujas & 15 & Alto \\
\hline C2.2.14 & $\begin{array}{l}\text { Ausência de canal de drenagem em torno do } \\
\text { mecanismo de bombeamento }\end{array}$ & 15 & Alto \\
\hline C2.2.15 & Presença de animais até 50 metros do poço. & 15 & Alto \\
\hline C2.2.16 & $\begin{array}{l}\text { A área da base do mecanismo de } \\
\text { bombeamento é permeável }\end{array}$ & 15 & Alto \\
\hline
\end{tabular}

Fonte: Corrêa (2020)

As Figuras 11 e 12 ilustram, respectivamente, as condições de manutenção local e os riscos suscetíveis na captação superficial em São Carlos (área de calibração) e na captação subterrânea em Araraquara (área de aplicação).

A maioria dos eventos perigosos $(53,2 \%)$ observados, praticamente em todas as propriedades rurais, localizou-se na etapa de captação superficial e subterrânea (Figuras 11 e 12).

Nesse sentido, pode-se dizer que o aumento de investimento em segurança e em procedimentos adequados nas captações pode reduzir significativamente

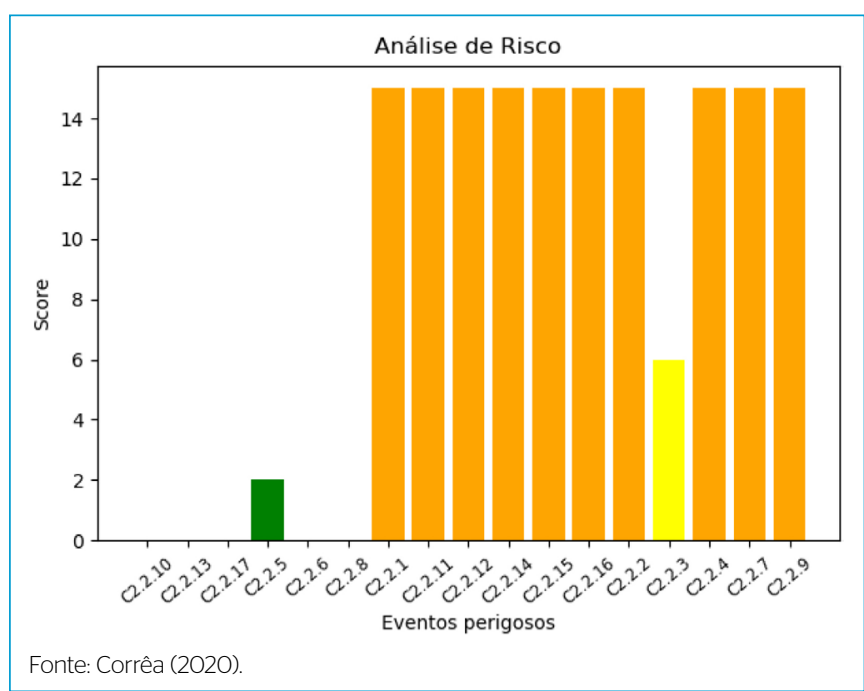

Figura 9-Riscos quantificados na captação de água subterrânea no assentamento rural em Araraquara (nov. 2019): Lote 1.

Quadro 7 - Análise de riscos para manancial subterrâneo (C2.2) em Araraquara (nov. 2019): lote 2.

\begin{tabular}{|l|r|c|c|}
\hline Código & Evento perigoso & Score & $\begin{array}{c}\text { Avaliação } \\
\text { de risco }\end{array}$ \\
\hline C2.2.2 & $\begin{array}{r}\text { Presença de água estagnada ao redor do poço, } \\
\text { devido à drenagem insuficiente }\end{array}$ & 4 & Baixo \\
\hline C2.2.3 & Ingresso de água contaminada durante inundações & 4 & Baixo \\
\hline C2.2.4 & Contaminação no equipamento de saída do poço & 6 & Médio \\
\hline C2.2.9 & $\begin{array}{r}\text { Presença de excrementos de animais } \\
\text { ou humanos em torno do poço }\end{array}$ & 6 & Médio \\
\hline C2.2.15 & Presença de animais até 50 metros do poço & 10 & Alto \\
\hline C2.2.16 & $\begin{array}{r}\text { A área da base do mecanismo } \\
\text { de bombeamento é permeável }\end{array}$ & 5 & Baixo \\
\hline C2.2.17 & $\begin{array}{r}\text { Existência de outra fonte de } \\
\text { poluição até 10 metros do poço }\end{array}$ & 15 & Alto \\
\hline
\end{tabular}

Fonte: Corrêa (2020) 


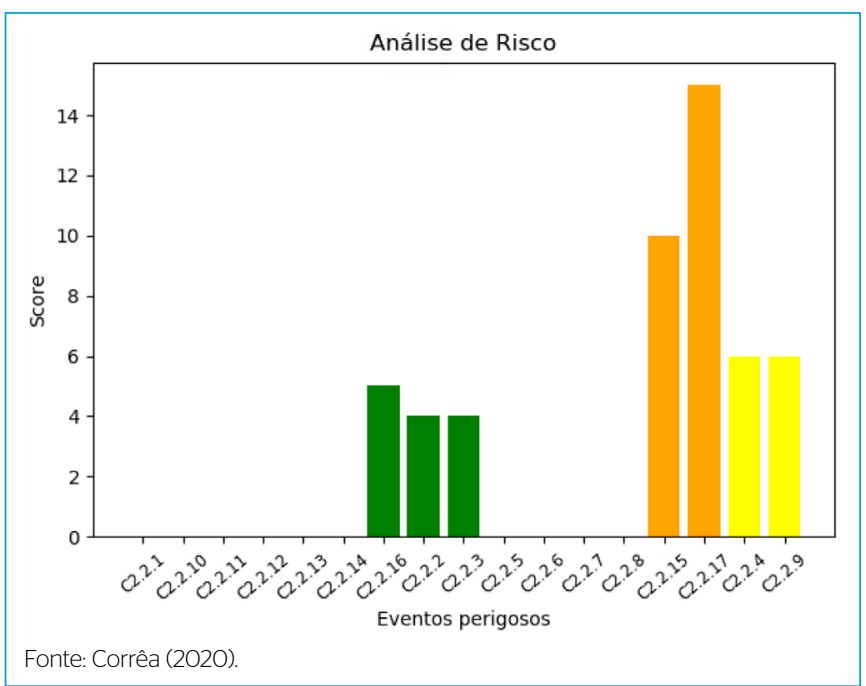

Figura 10 - Riscos quantificados na captação de água subterrânea no assentamento rural em Araraquara (nov. 2019): Lote 2.

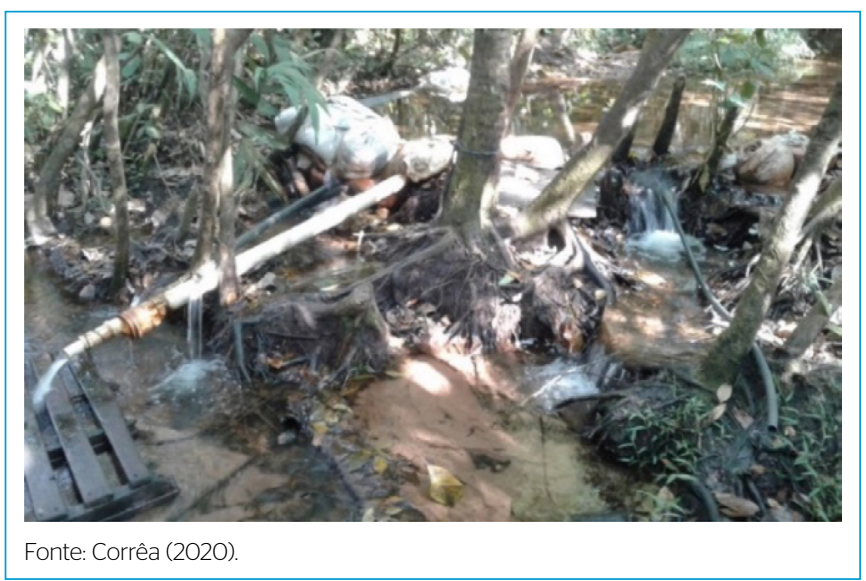

Figura 11 - Condições locais relativas à captação superficial em São Carlos (nov. 2019).

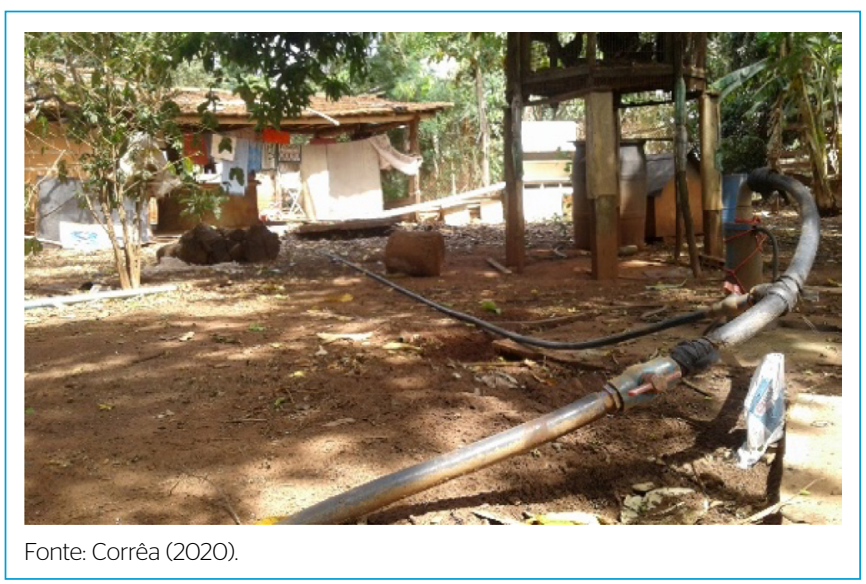

Figura 12 - Condições locais relativas à captação subterrânea em Araraquara (nov. 2019). os riscos à contaminação hídrica na região. O apoio de entidades de fomento ao produtor rural pode incentivar essa redução.

O software permitiu classificar os riscos selecionados pelo usuário, apontar recomendações mínimas para mitigar os danos e apresentar relatório para análise futura.

\section{CONCLUSÕES}

A segurança da água no contexto rural inclui o acompanhamento das condições sanitárias e ambientais das comunidades, o que pode ser alcançado pela identificação de riscos e priorização dos mais impactantes. A metodologia proposta permitiu a elaboração do modelo conceitual de PSA Rural para o monitoramento de riscos à contaminação da água.

A qualidade hídrica, no meio rural, pode ser afetada pela falta de adequação e de manutenção em qualquer uma das partes do sistema, principalmente quando ocorrem a captação de forma imprópria, a reservação precária e o uso direto da água sem tratamento. Cenários como esses potencializam os problemas de saúde pública e bem-estar da população, distanciando-se dos ODMs.

A revisão bibliográfica apontou que o setor rural carece de investimentos, infraestrutura, medicas socioeducativas e integração com o espaço urbano. A aplicação do software nas comunidades rurais constatou tal demanda e permitiu conhecer características intrínsecas a elas, subsidiando estudos futuros relacionados à salubridade rural.

Não há ferramentas disponíveis que forneçam o grau de risco de determinado evento perigoso na ruralidade. O programa concebido representa um mecanismo de prevenção, entre outros, que pode ser implementado em todo o território nacional para o PSA Rural.

O software é de fácil manipulação, pode ser instalado em qualquer computador, não exige acesso digital e não há necessidade de instalação prévia de aplicativo. Pode ser utilizado por consultores, técnicos de agências reguladoras, servidores do poder público, pesquisadores e outros usuários que atuam na prevenção ou avaliação de aspectos que interferem na qualidade hídrica e podem comprometer a segurança da água no meio rural.

Os eventos registrados nas visitas rurais foram similares aos observados em literatura, especialmente quanto ao uso de soluções individuais em cada propriedade. O grau de risco de cada evento amplia a capacidade de interpretação de aspectos qualitativos, especialmente, quando não há informações de parâmetros quantitativos para avaliação do saneamento rural.

A maior contribuição científica desta pesquisa foi a estruturação do software para o PSA Rural, abrangendo as etapas preliminares: (I) avaliação do sistema do PSA (II); plano de gestão (IV); e validação e verificação do instrumento elaborado (V). A etapa de monitoramento operacional (III) depende da aplicabilidade do software por pesquisadores, órgãos fiscalizadores ou instituições que prestam apoio técnico e fomento à ruralidade.

\section{CONTRIBUIÇÃO DOS AUTORES}

Correa, R. M. F.: Conceituação, Curadoria de Dados, Metodologia, Escrita Primeira Redação. Ventura, K. S: Conceituação, Curadoria de Dados, Análise Formal, Metodologia, Escrita - Revisão e Edição. 


\section{REFERÊNCIAS}

ASSOCIAÇÃO BRASILEIRA DE NORMAS TÉCNICAS (ABNT). NBR ISO 31000: Gestão de riscos - Diretrizes. Rio de Janeiro: Associação Brasileira de Normas Técnicas, 2018.

BRAGA, R.J.O. Diretrizes para proposição de Planos de Segurança da Água em Sistemas de Abastecimento Municipais Goianos. 74f. Dissertação (Mestrado) - Universidade Federal de Goiás, Goiânia, 2015.

BRASIL. Lei no 11.445, de 5 de janeiro de 2007. Estabelece as diretrizes nacionais para o saneamento básico. Brasília, 2007. 22 p.

BRASIL. Ministério das Cidades. Plano Nacional de Saneamento Básico (PLANSAB). Brasília: Ministério das Cidades, 2013.173 p.

BRASIL. Ministério das Cidades. Secretaria Nacional de Saneamento. Saneamento básico integrado às comunidades rurais: e populações tradicionais. Guia do profissional em treinamento - nível 2. Brasília: Ministério das Cidades, 2009. 100 p.

BRASIL. MINISTÉRIO DA SAÚDE. FUNDAÇÃO NACIONAL DE SAÚDE (FUNASA). Manual de saneamento. 5. edição. Brasília: Funasa, 2015. 547 p.

BRASIL. Ministério da Saúde. Fundação Nacional de Saúde. Programa Nacional de Saneamento Rural (PNSR). Brasília: Funasa, 2019. 266 p.

BRASIL. Ministério da Saúde. Portaria de Consolidação no 5. Consolidação das normas sobre as ações e os serviços de saúde do Sistema Único de Saúde. Brasília, 2017.

BRASIL. Secretaria de Vigilância em Saúde. Departamento de Vigilância em Saúde Ambiental e Saúde do Trabalhador (DSAST). Plano de Segurança da Água: Garantindo a qualidade e promovendo a saúde - Um olhar do SUS. Brasília: DSAST, 2012. 61 p.

CORRÊA, R.M.F. Elaboração de modelo conceitual para monitoramento de riscos à contaminação da água em comunidades rurais. 121f. Dissertação (Mestrado) - Programa de Pós-Graduação em Engenharia Urbana, Universidade Federal de São Carlos, São Carlos, 2020.

DORST, J. Antes que a natureza morra: por uma ecologia política. São Paulo: Edgard Blücher, 1973.

FALBO, R.A.; BARCELLOS, M.P. Engenharia de Software: notas de aula parte II. Espírito Santo: Universidade Federal do Espírito Santo / Curso de Engenharia da Computação, 2011. 117 p.

GARCÍA, R.; BLANCO, R.; ANTA, J; NAVES, A.; MOLINERO, J. Plan de seguridad del agua en los Campos de Refugiados Saharauis en Tindouf (Argelia). Ingeniería del Agua, v. 22, n. 1, p. 37-52, 2018. https://doi.org/10.4995/la.2018.7998

GOMEZ, A.P.; SORLINI, S.; COLLIVIGNARELLI, C. Water safety of improved source: the case study of Vilanculos (Mozambique). Procedia Environmental Science, Engineering and Management, v. 1, n. 1, p. 47-51, 2014.

GUNDRY, S.W.; WRIGHT, J.A.; CONROY, R.; DU PREEZ, M.; GENTHE, B.; MOYO, S.; MUTISI, C.; NDAMBA, J.; POTGIETER, N. Contamination of drinking water between source and point-of-use in rural households of South Africa and Zimbabwe: implications for monitoring the Millennium Development Goal for water. Water Practice and Technology, v. 1, n. 2, wpt2006032, 2006. https://doi.org/10.2166/wpt.2006.032
GUNNARSDÓTTIR, M.J.; GISSURARSON, L.R. HACCP and water safety plans in Icelandic water supply: Preliminary evaluation of experience. Journal of Water and Health, v. 6, n. 3, p. 377-382, 2008. https://doi.org/10.2166/ wh.2008.055

INSTITUTO BRASILEIRO DE GEOGRAFIA E ESTATISTICA (IBGE). Pesquisa Nacional por Amostra de Domicílios. Rio de Janeiro: IBGE, 2015.

ITN-BUET. Water Safety Plan for Hand tubewell in Rural Water Supply System. Bangladesh, 2006. $16 \mathrm{p}$.

MANCUSO, P.C.S.; SOUZA, R.M.G.L. Princípios e métodos utilizados em Segurança da Agua para consumo humano. In: FONSECA, F.H.B.P. (org.) Plano de Segurança da Água na visão de especialistas. São Paulo: SETRI, 2015. 451 p. p. 49-64.

MARTINHO, C:; MENDES, R. Plano de Segurança da Água, um desafio. In: FONSECA, F.H.B.P. (org.). Plano de Segurança da Água na visão de especialistas. São Paulo: SETRI, 2015. 451 p. p. 95-104.

MAYNILAD WATER SERVICES. Maynilad Water Safety Plan 2019. Managing Drinking-Water Quality from Catchment to Consumer. Filipinas: Maynilad Water Services, 2019. 189 p.

MELLANBY, K. Biologia da poluição. 2a ed. São Paulo: EPU-USP, 1982.

NIJHAWAN, A.; JAIN, P.; SARGAONKAR, A.; KUMAR LABHASETWAR, P. Implementation of water safety plan for a large-piped water supply system. Environmental Monitoring \& Assessment, v. 186, n. 9, p. 5547-5560, 2014. https://doi.org/10.1007/s10661-014-3802-x

ORGANIZAÇÃO DAS NAÇÕES UNIDAS (ONU). Objetivos de Desenvo/vimento Sustentável. Transformando Nosso Mundo: A Agenda 2030 para o Desenvolvimento Sustentável. ONU, 2019. 49 p.

RASHON. Guía para la implementación de Planes de Seguridad de Agua en el Sector Rural de Honduras. Red de Agua y Saneamiento de Honduras, 2009. 65 p.

RONDI, L. The Water Safety Plan approach: elaboration, implementation and evaluation in rural contexts of sub-Saharan Africa. 330f. Tese (Doutorado) Brescia, 2014.

SILVA, P.C. Análise da qualidade da água no sistema de abastecimento de Itaipava/RJ, visando a implantação do Plano de Segurança da Água. 68f. Dissertação (Mestrado) - Escola Politécnica \& Escola de Química, Universidade Federal do Rio de Janeiro, Rio de Janeiro, 2013.

SOMMERVILLE, I. Engenharia de Software. 6a ed. São Paulo: Pearson, 2004. $592 \mathrm{p}$.

SORLINI, S.; BIASIBETTI, M.; ABBÀ, A.; COLLIVIGNARELLI, M.C.; DAMIANI, S. Water Safety Plan for drinking water risk management: the case study of Mortara (Pavia, Italy). Ambiente e Água, v. 12, n. 4, p. 513-526, 2017. https://doi. org/10.4136/ambi-agua.2102

VENTURA, K.S.; VAZ FILHO, P.; NASCIMENTO, S.G. Plano de segurança da água implementado na estação de tratamento de água de Guaraú, em São Paulo. Engenharia Sanitária e Ambiental, v. 24, n. 1, p. 109-199, 2019. https:// doi.org/10.1590/S1413-41522019169881 
VIEIRA, J.M.P.; MORAIS, C. Planos de Segurança da Água para Consumo Humano em Sistemas Públicos de Abastecimento. Minho: Universidade do Minho/Instituto Regulador de Água e Resíduos, 2005. 178 p.

VILAR, P.A.G. Programa Nacional de Saneamento Rural. In: SEMINÁRIO FRANCO-BRASILEIRO SOBRE SAÚDE AMBIENTAL, 1., 2011. Anais [...]. 2011. Disponível em: http://www.fiocruz.br/omsambiental/media/ ProgramaNacionaldeSaneamentoRural.pdf. Acesso em: 10 set. 2018.

WORLD BANK. Water and Sanitation Program. Water Safety Plans for Rural Water Supply in India. Policy Issues and Institutional Arrangements. Nova Délhi: World Bank, 2010.

WORLD HEALTH ORGANIZATION (WHO). Guidelines for drinking-water quality: fourth edition incorporating the first addendum. Genebra: WHO, 2017. $631 \mathrm{p}$.
WORLD HEALTH ORGANIZATION (WHO). Water safety plan: a field guide to improving drinking-water safety in small communities. Genebra: WHO, 2014. $100 \mathrm{p}$.

WORLD HEALTH ORGANIZATION (WHO). Water Safety Plans. Managing drinking-water quality from catchment to consumer. Genebra: WHO, 2005. $244 \mathrm{p}$.

WRIGHT, J.; GUNDRY, S.; CONROY, R. Household drinking water in developing countries: A systematic review of microbiological contamination between source and point-of-use. Tropical Medicine and International Health, v. 9, n. 1, p. 106-117, 2004. https://doi.org/10.1046/j.1365-3156.2003.01160.x

YE, B.; CHEN, Y.; LI, Y.; LI, H.; YANG, L.; WANG, W. Risk assessment and water safety plan: Case study in Beijing, China. Journal of Water and Health, v. 13, n. 2. p. 510-521, 2015. https://doi.org/10.2166/wh.2014.101 